\title{
Growth Pattern And Nutritional Status Of Under Five Children In Owo Local Government Area Of Ondo State, Nigeria.
}

\author{
Mustapha, R.A. Bolajoko O.O. \\ Department of Nutrition and Dietetics, Faculty of Food Technology, Rufus Giwa Polytechnic, P.M.B. 1019, \\ Owo Ondo State, Nigeria.
}

\begin{abstract}
The growth pattern and nutritional status of under five children in Owo Local Government Area of Ondo State was assessed between May and November, 2009 to know if their growth were normal or constitute public health problem. A total of 600 randomly selected male and female under-five children were surveyed using anthropometry. 120 infants (0.5-12 months old) were randomly selected from 15 primary hath centres while 480 children (aged 13-60 months) were randomly selected from crèche and nursery schools. Anthropometric measurements of subjects such as weight, height and MVAC were obtained. Data were analyzed using EPI-Info 2000 nutritional software. Findings show that majority of the children's growth in height and weight slightly fall below CDC/NCHS growth curve at $50^{\text {th }}$ percentile of reference population when compared. Overall mean weight, height and MUAC of the children were $10.6 \mathrm{~kg}, 78.5 \mathrm{~cm}$ and $16.3 \mathrm{~cm}$ respectively. $17 \%$ and $43 \%$ of all the children were stunted and underweight, while $9 \%$ and $6 \%$ were severely stunted and underweight (z-score <-3 S.D). Chronic and severe or acute form of malnutrition affects child's mental capability; it erodes attention span and learning process. It is one of the highest causes of morbidity and mortality. Even stunting among the potential female mothers can bring about maternal morbidity and obstructed child labour, which becomes a recycle generational problem particularly through the female life course.
\end{abstract}

Keywords: children, Growth pattern, Nutritional status, Malnutrition.

\section{Introduction}

In developing countries like Nigeria, poverty in early childhood are some major reasons for longer period of height attainment and short adult stature (World Bank, 2006). The size and composition of the body is determined by interaction between genetics and nutrition. And the assessment of these size and body compositions particularly using anthropometry in children not only serves as a means of evaluating the health and nutritional status. It is also a reflection of household income, food consumption pattern and excellent measurement of inequalities in human growth pattern (De Onis et al, 2000; Micklewright, 2000). Undernutrition is an underlying cause of growth retardation, infection and death among children in Nigeria.

This makes prevention of under-nutrition in children one of the top priorities in efforts to reduce childhood mortality (Caulfield et al, 2004). The effects of malnutrition on children are not limited to physical growth, but extend to mental, social and spiritual wellbeing. They could be transmitted from generation to another constituting a vicious spiral cycle (Gillespie et al, 1993). Contrary to common use, the term malnutrition refers not only to deficiency stated, but also to excess or imbalance in intake of calories, proteins and/or other nutrients (WHO 2006). Health and nutritional problems during childhood are the result of a wide range factors mostly related to unsatisfactory food intake, severe and repeated infections or a combination of the two (De Onis et al, 2004). Child nutritional status is an essential component and index of a country's overall human development. There is a growing consensus that poor nutritional status during childhood can have long lasting consequences into adulthood, both in terms of health and mortality and in terms of other measures of human capital (Maluccio et al, 2005).

Growth of children occurs in spurts and plateaus, but overall growths patterns are predictable. If a child's overall pattern of growth changes, his dietary intake should be evaluated to determine the reason for the sudden change. There are critical periods in childhood when malnutrition can cause lasting damage to growth for which adequate nutrition later may not be able to compensate leading to stunting.

Stunting can co-exist with underweight or overweight/obesity (Doak et al, 2005). The WHO recommends that developing countries monitor the co-existence of stunting and overweight in children, because these are risk factors for chronic disease in adulthood (Gillespie et al, 1993). Various studies in Nigeria had shown that there is high prevalence of under-nutrition among under five children. However, this study is designed to assess the growth pattern and nutritional status of under five children in Owo Local Government Area of Ondo State, Nigeria with a view to evaluate their growth pattern and to know if this will constitute public health problem in Owo community. 


\section{Study Design}

\section{Materials And Methods}

This study was a descriptive cross sectional survey of under five children in Owo Local Government Area of Ondo State.

\section{Location And Period Of Study}

This study was carried out between September 2009 to January 2010 in Owo Local Government Area in Ondo State. Owo is an ancient town located in Ondo state, Southwestern part of Nigeria. There are fifteen wards in Owo Local Government. These wards cut across Owo town and adjourning towns which include - , Molege, Isijogun, Uso, Isuada and Ago Panu. Samples were selected from the fifteen (15) primary health centres, crèche and nursery schools available in these towns.

\section{Sample Size and Selection}

A total of six hundred (600) male and female under five children were randomly selected for the study. One hundred and twenty (120) male and female infants (0-12 months) were randomly selected from the fifteen (15) primary health centres available in all the wards. Four hundred and eighty (480) children aged 13-0 months were randomly selected from crèche and nursery schools among randomly selected schools in Owo Local Government.

\section{Ethical Consideration and Informed consent}

The study was approved by the primary health centre of the Owo Local Government authority while written consent was obtained from the Parent Teacher Association of each school and individual parents.

\section{Data Collection}

Anthropometric measurement was the research instrument used for data collection in this study. Data on anthropometric measurement was collected through standard procedures (Lohman et al, 1988; United Nations, 1986). The major anthropometric measured parameters were weight, length/height, and mid upper height circumference (MUAC) of the children. All children were weight on infant/baby scale with a maximum capacity of $25 \mathrm{~kg}$ (graduated in $100 \mathrm{~g}$ ). Infants were weight completely undressed while the older children were weighed with minimal underwear. Weight was recorded to the nearest $0.1 \mathrm{~kg}$. Children less than two years of age were assessed for recumbent length to the nearest millimeter.

Precautions were made using the plastic SECA-type baby length board. One examiner held the child's head and applied gentle pressure to bring the top of it into contact with

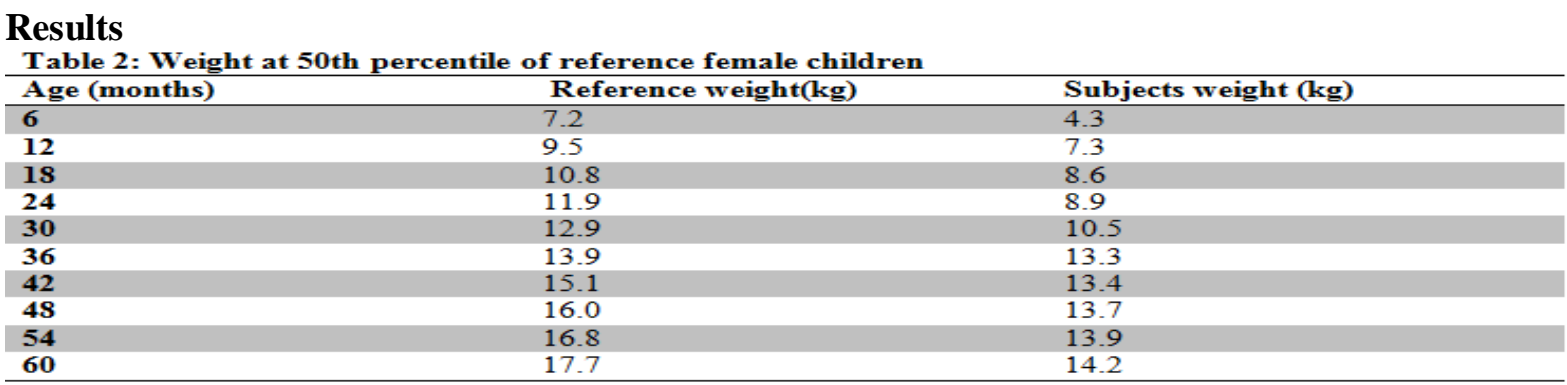

\begin{tabular}{|c|c|c|}
\hline Age (months) & Boys Reference height (cm) & Subjects height (cm) \\
\hline 6 & 67.8 & 56.4 \\
\hline 12 & 76.1 & 67.3 \\
\hline 18 & 82.4 & 68.9 \\
\hline 24 & 87.6 & 74.3 \\
\hline 30 & 92.3 & 80.7 \\
\hline 36 & 96.5 & 81.4 \\
\hline 42 & 98.4 & 82.3 \\
\hline 48 & 102.3 & 88.1 \\
\hline 54 & 106.0 & 95.7 \\
\hline 60 & 109.4 & 101.8 \\
\hline
\end{tabular}


Table 3: Weight at 50th percentile of reference male children

\begin{tabular}{lll}
\hline Age (months) & Boys Reference height $(\mathbf{c m})$ & Subjects height $(\mathbf{c m})$ \\
\hline $\mathbf{6}$ & 7.8 & 5.4 \\
$\mathbf{1 2}$ & 10.2 & 8.2 \\
$\mathbf{1 8}$ & 11.5 & 9.4 \\
$\mathbf{2 4}$ & 12.6 & 10.2 \\
$\mathbf{3 0}$ & 13.7 & 10.5 \\
$\mathbf{3 6}$ & 14.7 & 12.1 \\
$\mathbf{4 2}$ & 13.2 & 13.7 \\
$\mathbf{4 8}$ & 14.8 & 14.0 \\
$\mathbf{5 4}$ & 15.7 & 14.8 \\
$\mathbf{6 0}$ & 16.6 & 15.9 \\
\hline
\end{tabular}

Figure 1 Growth Pattern of Children (weight)

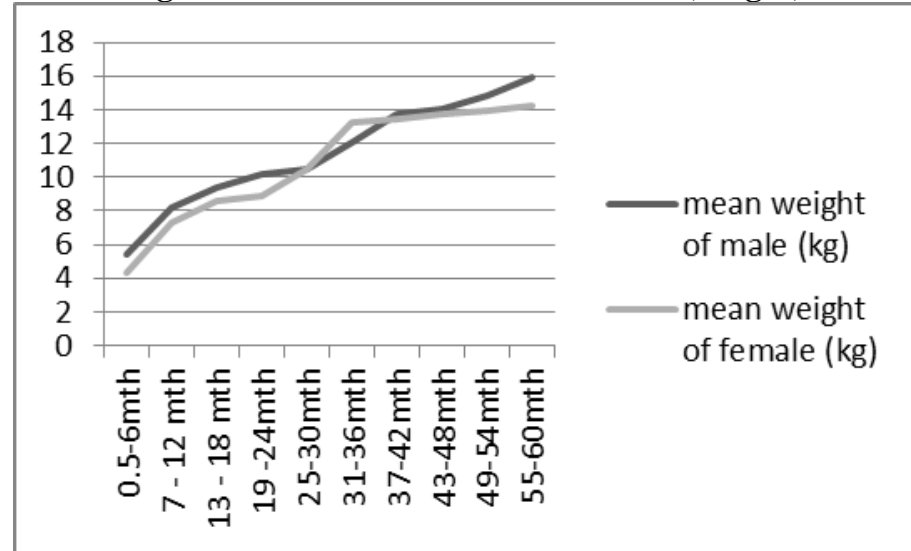

Figure 2 Growth Pattern of Children (height)

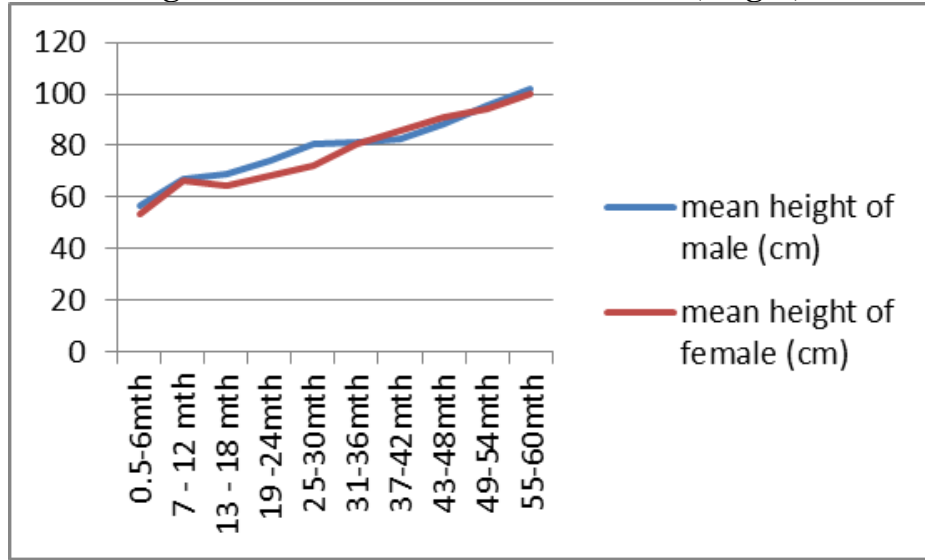

Table 4 Nutritional status of Children

\begin{tabular}{lll}
\hline Nutritional status & No & \% \\
\hline Moderately stunted & 102 & 17 \\
Severely stunted & 54 & 9 \\
Moderately underweight & 258 & 43 \\
Severely underweight & 36 & 6 \\
\hline
\end{tabular}

\section{Discussion}

The challenges of malnutrition and the mortality of infants and under - five children poses a great deal of Public Health and Welfare problems among children in Nigeria (UNICEF, 2000). According to this study, moderate stunting was found to be $17 \%$, while moderate under nutrition was $43 \%$. This correlates with the study that showed that stunting can co-exist with underweight or overweight/obesity (Doak et al, 2005). Many children are underweight, stunted, thin as a result of nutritional inadequacy, which prevent them from reaching 
their uptimum potential (ACC/SCN,1993). Malnutrition has been identified to affect the continue development children of the children (Pollit el at, 1995). Throughout the world, over half of deaths of young children can be attributed to under nutrition (Caulifiedle et. al, 2004).

This is a great threat to national development because good nutrition in early life is crucial for optimal growth and mental development which is the pillar for social and economic development. According to WHO, 1993, malnutrition has continuued to be public health problem in developing countries where the poor socio-economic condition has continued to work in synergy with malnutrition. However, stunting and malnutrition have been found to be a reflection of household income, food consumption pattern and excellent measurement of inequalities in human growth pattern (De Onis et al, 2000). This study agrees with Micklewright, 2000 that showed that growth pattern of children are quite different.

Children in most poor and developing countries are living on poor nutritional intake. In developing countries like Nigeria, poverty in early childhood are some major reasons for longer period of height attainment and short adult stature (World Bank, 2006). Nutrition has been proven to be the foundation on which human progress in built. Well-nourished children perform better in school; grow into healthy adult and in-turn give their children better start in life (Veneman, 2007). Sadly, the effects of malnutrition on children are not limited to physical growth, but extend to mental, social and spiritual wellbeing. They could be transmitted from generation to another constituting a vicious spiral cycle (Gillespie et al, 1993).

\section{Conclusion And Recommendations}

It was found from the result of this study that prevalence of stunting and underweight was found to be higher among the children. This portend public health problems since chronic and severe form of malnutrition affects child mental capability, eroding attention span and learning process and even stunting among females lead to obstructed labour during childbirth in the future. It becomes a recycled generational problem particularly through females.

Therefore, Government, Nutritionists, other health workers, WHO, UNICEF should put more effort into promoting young children health status in Owo Local Government and Nigeria as a whole by giving appropriate legislation and food policies that will improve household food and nutrition security, nutrition education, creation of incentives and safety nets that will gear up the socio-economic status of their parents.

The health worker should help by promoting family planning campaign to educate the population on the demerits of large family on household food security and family health.

\section{References}

[1] ACC/SCN (1993) Malnutrition and infection. A review Committee on Coordination/ Subcommittee or Nutrition, Neverlands.

[2] Caulfield LE, de Onis M, Blossner M, Black RE. (2004)Under-nutrition as an underlying cause of Child Deaths Associated with Diarrhea, Pneumonia, Malaria and Measles. JAMA 80:193-8

[3] CDC/NHC (2000). CDC Growth Charts; United States. http/WWW.edu.gov/groth charts. Posted May 30-3000 on the internet.

[4] Child Growth Standards and World Health Organization (2006) (http://who.int/childgrowth).

[5] De Onis M, Blossner M, Borghi E, Frongillo EA, Morris R. (2004) Estimates of global prevalence of childhood underweight in 1990 and 2015. JAMA 291:2600-6

[6] Doak CM, Adair LS, Benthley M, Monteiro C, Popkin BM. (2005). The dual burden household and the household and the nutrition paradox. Int Obes 29:129-36.

[7] Gillespie, Mason J, Martorell R. (1993): How nutrition improves in states of the art series United Nations Administrative Committee on Coordination- Sub committed on Nutrition (Acc/SCN).

[8] Maluccio, J.A, J. Hoddinolt, J.R. Berhman, R. Martonell, A. Dvsumbing and A.D. Stein (2005). The impact of an Experimental Nutritional Intervention on Education into Adulthood in Rural Guatemala Working Paper.

[9] Pollit - E(1997) iron deficiency and educational deficiency, Nutr Rev. 55 (4) : 133-140

[10] United Nations (1986): How to weigh land measure children: in household

[11] United Nations International Children Education Fund \{UNICEF\}. State of the world children. New York ps 862000.

[12] Veneman, A.M (2007) $30^{\text {th }}$ SCN Annual session symposium on to end child hunger and under nutrition. UNICEF. Geneva

[13] WHO measuring changes in nutritional status guidlines for Assessing the nutritional impact of supplementary feeding programme WHO Guneva (1993) 